\title{
5-Aminoimidazole and its Riboside from Biotin-Deficient Yeast
}

\author{
By J. D. WOODWARD* AND C. RAINBOW \\ Department of Applied Biochemistry, \\ University of Birmingham
}

(Received 28 November 1960)

\begin{abstract}
SUMMARY
A purified preparation of the 'amine' which accumulated in the medium during the growth of a strain of Saccharomyces cerevisiae (yeast 47) under conditions of partial biotin-deficiency contained two compounds, one of which was chromatographically and electrophoretically identical with synthetic 5-aminoimidazole. Both compounds gave identical colours on diazotization and coupling in the Bratton $\&$ Marshall reaction and on treatment with the Pauly imidazole reagent. The other, and major, component of purified 'amine' was shown to be 5-aminoimidazole riboside by its conversion to the free base and ribose on incubation with a bacterial nucleosidase. Synthetic 5-aminoimidazole gave analytical figures for formate, $\mathrm{NH}_{3}-\mathrm{N}$ and total-N similar to those previously obtained for purified 'amine'. Evidence was obtained that resting organisms of a mutant Escherichia coli converted 'amine' and synthetic 5-aminoimidazole to 5-amino-4-imidazole-carboxamide. One of the adenine derivatives which accumulated instead of 'amine' and hypoxanthine in a medium supplemented with aspartate was tentatively identified as thiomethyladenosine.
\end{abstract}

\section{INTRODUCTION}

Previous papers (Chamberlain, Cutts \& Rainbow, 1952; Chamberlain \& Rainbow, 1954; Lones, Rainbow \& Woodward, 1958) described the accumulation of diazotizable amine ('amine') and hypoxanthine in culture filtrates of Saccharomyces cerevisiae (yeast 47) after growth in a biotin-deficient defined medium which contained L-methionine. 'Amine' accumulation was invariably associated with the formation of a pink pigment by the organism. Addition of adenine or aspartate to the medium suppressed the production of this pigment and the accumulation of 'amine' and hypoxanthine. These results were regarded as indicating that a derangement in adenine biosynthesis was conditioned by biotin deficiency. Preliminary studies on a purified preparation indicated that 'amine' was 5-aminoimidazole riboside. In the present paper, evidence is presented which, in conjunction with that already reported, identifies beyond reasonable doubt the chief components of purified 'amine' as 5-aminoimidazole and its riboside, the latter being the major component.

* Present address: Department of Physiological Chemistry, University of Reading. 


\section{METHODS}

Preparation of 'amine'. Purified 'amine' was prepared from culture filtrates of Saccharomyces cerevisiae (yeast 47) grown on a defined medium containing DLmethionine $(500 \mu \mathrm{g} . / \mathrm{ml}$.) and D-biotin $(0.02 \mathrm{~m} \mu \mathrm{g} . / \mathrm{ml}$.). Details of the organism, its maintenance and cultivation, and of the purification of 'amine' were as given by Lones et al. (1958), except: (a) the final eluate was concentrated by lyophilization; (b) by using proportionately larger ion-exchange resin columns, a total of 21 . culture filtrate, yielding $\mathbf{2 8 - 3 8} \mathrm{mg}$. crystalline material, was handled. These preparations are referred to as purified 'amine' and were used as the chief experimental material in this work.

Preparation of synthetic 5-aminoimidazole. An aqueous solution of 5(4)-aminoimidazole was prepared freshly as required by catalytic reduction of 5(4)-nitroimidazole (Rabinowitz, 1956).

Experiments with suspension of organisms. Resting suspensions of Escherichia coli $\mathrm{B} 96$ were used, according to the procedure described by Gots (1950), to demonstrate the conversion in vivo of 'amine' to 5(4)-amino-4(5)-imidazolecarboxamide, which accumulates with this purineless mutant. The organism was grown for $24 \mathrm{hr}$. at $37^{\circ}$ in $200 \mathrm{ml}$. portions of a medium consisting of glucose $(0 \cdot 2 \%, \mathrm{w} / \mathrm{v})$, tryptone $(2 \%, \mathrm{w} / \mathrm{v})$, and hypoxanthine $(20 \mu \mathrm{g} . / \mathrm{ml}$.$) . The organisms were harvested$ by centrifugation, washed twice with $0.85 \%(\mathrm{w} / \mathrm{v})$ saline and resuspended in $1 \mathrm{ml}$. $0.85 \%(w / v)$ saline.

Complete reaction mixtures $(6 \cdot 1 \mathrm{ml}$.) contained 0.13 M-phosphate buffer ( $\mathrm{pH} \mathrm{7.2}$; $3 \mathrm{ml}$.), $0.02 \mathrm{M}$-glucose $(3 \mathrm{ml}$.$) , purified 'amine' solution (20 \mu \mathrm{l}$.) and organism suspension $\left(0 \cdot 1 \mathrm{ml}\right.$.). Reaction mixtures were incubated for $3 \mathrm{hr}$. at $37^{\circ}$, after which the organisms were centrifuged down, and the clear supernatant fluids submitted to the Bratton \& Marshall diazotization procedure (see below). The absorption maxima of the colours thus produced were determined spectrophotometrically.

Preparation of bacterial nucleosidase. The bacterial nucleosidase used in this work was an unpurified extract of Lactobacillus brevis L 4. This organism was grown on $500 \mathrm{ml}$. portions of the medium described by Chamberlain \& Rainbow (1954) except that glucose was omitted and maltose monohydrate $\left(2 \%\right.$, w/v) and $\mathrm{CH}_{3} \mathrm{COONa}_{3} 3 \mathrm{H}_{2} \mathrm{O}$ $(0.4 \%, \mathrm{w} / \mathrm{v})$ were included. After incubation at $28^{\circ}$ for $24 \mathrm{hr}$., the organisms were harvested (centrifuge), washed twice with $1 \%(\mathrm{w} / \mathrm{v}) \mathrm{KCl}$ solution, resuspended in $5 \mathbf{m l}$. of that solution, and then disrupted in a tissue disintegrator (H. Mickle, Gomshall, Surrey) with ballotini beads $(\mathbf{0} \cdot 2-0 \cdot 3 \mathrm{~mm}$. diameter). During the process the temperature was kept below $5^{\circ}$ by alternating cycles $(5 \mathrm{~min}$.) of shaking and cooling in ice. The disrupted suspension was poured off from the beads and centrifuged at $2^{\circ}$ to remove cell debris. The supernatant fluid was used immediately, or stored at $-20^{\circ}$ at which temperature it retained its nucleosidase activity for at least 2 months. This extract readily hydrolysed adenosine to adenine and ribose.

\section{Analytical methods}

Diazotizable amine. This was determined by the colour produced in the Bratton \& Marshall diazotization and coupling procedure as described by Chamberlain \& Rainbow (1954). 
Pauly reaction. This was performed on solutions in accordance with the modification suggested by Koessler \& Hanke (1919) or on paper by the modification introduced by Ames \& Mitchell (1952).

Ribose. In solutions this was determined by the orcinol method of Drury (1948). On paper chromatograms and electrophoretograms, free ribose was detected by aniline hydrogen phthalate and compared with authentic D-ribose as marker. Combined ribose was detected directly on paper by the lead tetra-acetate method of Buchanan, Dekker \& Long (1950) and, after elution, by the orcinol method.

Purine and purine derivatives. These were detected on paper chromatograms and paper electrophoretograms by ultraviolet photography. After elution, absorption spectra were determined in an S.P. 500 quartz spectrophotometer (Unicam, Cambridge).

Paper chromatography. A conventional descending solvent technique, with Whatman no. 3 or no. 4 paper and (unless otherwise stated) the butanol + acetic acid + water $(125+30+125)$ solvent of Woiwod (1949), was used.

Paper electrophoresis. This was carried out in $0.05 \mathrm{~m}$-buffer solutions, with 22 in. strips of Whatman no. 3 paper in an enclosed strip technique. Voltages of 2000$3000 \mathrm{~V}$. were usually used.

\section{RESULTS}

\section{Chromatographic and electrophoretic behaviour of purified 'amine'}

When subjected to paper chromatography or paper electrophoresis samples (about $500 \mu \mathrm{g}$.) of purified 'amine' gave two major diazotizable spots (see also Lones et al. 1958). Table 1 summarizes some of the properties of the components thus separated.

Table 1. Properties of two diazotizable materials separable from purified 'amine'

\begin{tabular}{|c|c|c|c|c|c|c|}
\hline $\begin{array}{l}\text { om- } \\
\text { onent }\end{array}$ & $R_{F}$ value & $\begin{array}{l}\text { Electro- } \\
\text { phoretic } \\
\text { migration }\end{array}$ & $\begin{array}{c}\text { Bratton \& } \\
\text { Marshall colour } \\
\left(\lambda_{\text {max }} ; \mathrm{m} \mu\right)\end{array}$ & $\begin{array}{l}\text { Pauly } \\
\text { colour }\end{array}$ & Pentose & Phosphate \\
\hline Iajor & 0.33 & $22 \cdot 5$ & $\begin{array}{l}\text { Orange-red } \\
(500)\end{array}$ & Yellow & Present & Absent \\
\hline linor & 0.46 & $37 \cdot 7$ & $\begin{array}{l}\text { Orange-red } \\
(500)\end{array}$ & Blue & Absent & Absent \\
\hline
\end{tabular}

The results indicated that the slower-moving compound (chromatographically; electrophoretically) was an imidazole riboside derivative, while the faster-moving one was the corresponding free base, as Lones et al. (1958) had found. The riboside was quantitatively the major constituent. Supporting evidence was obtained by electrophoresis at different $\mathrm{pH}$ values. At more acid $\mathrm{pH}$ values, the ionization of the diazotizable amino group was enhanced and migration increased: at less acid $\mathrm{pH}$ values, the opposite behaviour was observed (Table 2). The results with borate buffer ( $\mathrm{pH}$ 10) were particularly significant. This buffer has been used for the electrophoretic separation of sugars (Foster, 1952), the borate ion complexing with 
the free hydroxyl groups of the sugar and giving good migrations towards the anode. In borate buffer the migration of the riboside was reversed, while the free base continued to migrate towards the cathode but at a much decreased rate because of the suppression of ionization of the amino group at $\mathrm{pH}$ 10. Ascending chromatography in a solvent consisting of $85 \%(\mathrm{w} / \mathrm{v})$ ammonium bicarbonate in water (Hems, 1959) also reversed the order in which the diazotizable spots separated. This behaviour was consistent with the proposed relationship between the two substances, the presence of the ribose moiety conferring on the riboside more hydrophilic properties.

\section{Table 2. Electrophoretic behaviour of the diazotizable constituents of purified 'amine' preparations}

Spots $(20 \mu \mathrm{l}$.) were applied to Whatman no. 4 paper and migration measured after $50 \mathrm{~min}$. application of $\mathbf{3 0 0 0} \mathrm{V}$.

\begin{tabular}{|c|c|c|}
\hline \multirow[b]{3}{*}{ Buffer } & \multicolumn{2}{|c|}{ Migration } \\
\hline & Riboside & Free base \\
\hline & direction & direction \\
\hline Formate ( $\mathrm{pH} \mathbf{3 \cdot 5})$ & 31.5 ; to cathode & 51.5 ; to cathode \\
\hline Acetate (pH 5.0) & 22.5 ; to cathode & $37 \cdot 7$; to cathode \\
\hline Phosphate (pH $7 \cdot 0)$ & $10 \cdot 3$; to cathode & $15 \cdot 7$; to cathode \\
\hline Borate (pH 10.0) & $11 \cdot 3 ;$ to anode & $6.4 ;$ to cathode \\
\hline
\end{tabular}

Identity of the free-base component of 'amine' preparations with 5(4)-aminoimidazole

Synthetic 5-aminoimidazole gave a strong orange-red Bratton \& Marshall colour with an absorption maximum $(500 \mathrm{~m} \mu)$ identical with that given by purified 'amine' preparations. The chromatographic mobilities of the synthetic material and the free-base constituent of 'amine' were identical, as were their electrophoretic migrations at $\mathrm{pH}$ values $3 \cdot 5,5 \cdot 0,7 \cdot 0$ and at $\mathrm{pH} 10 \cdot 0$ (in borate buffer). In the Pauly reaction, the synthetic material and the free-base component gave identical blue colours.

The ultraviolet absorption spectrum of the purified 'amine' used in this work differed slightly from that reported by Lones et al. (1958) in that the feeble peak at $238 \mathrm{~m} \mu$ was absent. The elimination of this peak may have been the result of the somewhat improved method of 'amine' preparation used.

Samples of synthetic 5-aminoimidazole were hydrolysed and then analysed for formic acid, ammonia and total-N by the methods described by Lones et al. (1958). For two different preparations the molar ratios of formate: $\mathrm{NH}_{3}-\mathrm{N}$ : total-N (referred to $\mathrm{NH}_{3}-\mathrm{N}$ as 2) were $1: 2: 4$ and $0 \cdot 93: 2: 4$. Considering the great instability of 5-aminoimidazole and that only unpurified aqueous solutions were available for analysis, these values compared fairly well with the theoretical ratio of $1: 2: 3$, and with the ratios obtained by Lones et al. (1958) for purified 'amine'. The possible presence of small quantities of unchanged nitroimidazole may be a cause of the high figures for total-N in the synthetic material. 


\title{
Enzymic hydrolysis of the riboside component
}

Portions of purified 'amine' solution containing about $400 \mu \mathrm{g}$. were incubated for $24 \mathrm{hr}$. with $0.5 \mathrm{ml}$. Lactobacillus brevis $\mathrm{L} 4$ extract. After concentration in vacuo at room temperature, samples of the reaction mixtures, together with reference spots of D-ribose and synthetic 5-aminoimidazole, were chromatographed and examined for diazotizable compounds and for free ribose. The chromatograms showed that extensive but not complete hydrolysis of 'amine' had occurred, the amount of free-base component and of free ribose had increased, and the amount of riboside component had diminished. These changes did not take place when boiled L 4 extract was substituted for unboiled extract. Under the above conditions adenosine, guanosine, inosine, xanthosine and cytidine underwent extensive hydroiysis in $3 \mathrm{hr}$. by the bacterial extract, whereas a much longer period (12 hr.) was required before the riboside component of 'amine' underwent appreciable hydrolysis. This slow rate of action may reflect the pseudo-nucleoside structure of the 'amine' riboside substrate, in which an imidazole derivative takes the place of the 'enzymically preferable' purine or pyrimidine moiety of normal nucleosides.

Table 3. Conversion of 'amine' to a new diazotizable substance by Escherichia coli $B 96$

\begin{abstract}
The complete reaction mixture contained: $0.13 \mathrm{~m}$-phosphate buffer ( $\mathrm{pH} 7 \cdot 2 ; 3.0 \mathrm{ml}$.); $0.02 \mathrm{M}$-glucose $(3.0 \mathrm{ml}$ ) ; purified 'amine' solution (about $600 \mu \mathrm{g}$. in $20 \mu \mathrm{l}$.); $0.1 \mathrm{ml}$. washed suspension of $E$. coli B96. The colour was that obtained when the Bratton \& Marshall procedure was applied to the supernatant fluids after reaction had proceeded for $3 \mathrm{hr}$. at $37^{\circ}$.
\end{abstract}

\begin{tabular}{|c|c|c|}
\hline \multirow[b]{2}{*}{ Reaction mixture } & \multicolumn{2}{|c|}{ Colour } \\
\hline & Visual & $\left(\lambda_{\max } \operatorname{m} \mu\right)$ \\
\hline Complete & Purple & $\mathbf{5 2 0}$ \\
\hline 'Amine' omitted & Colourless & - \\
\hline Organisms omitted & Orange-red & 499 \\
\hline Phosphate omitted & Orange-red & 499 \\
\hline Glucose omitted & Orange-red & 500 \\
\hline Complete + boiled organisms & Orange-red & 499 \\
\hline
\end{tabular}

\section{Conversion of 'amine' to 5-amino-4-imidazole carboxamide in vivo}

The change in colour developed on diazotization and coupling with the Bratton \& Marshall reagents has been used as an index of the conversion of 5-aminoimidazole to 5-amino-4-imidazolecarboxamide (Love \& Gots, 1955; Friedman \& Moat, 1958). The changes which occurred in the reaction mixture when freshly prepared 'amine' solutions were incubated with washed suspensions of Escherichia coli B96 are recorded in Table 3 which shows that, in a complete system for which living organisms, glucose and inorganic phosphate were all essential, there was produced diazotizable material giving a purple colour, quite distinct from the orange-red colour given by 'amine' itself. The absorption maximum of this material $(520 \mathrm{~m} \mu)$ which gave the purple colour was nearer that of 5-amino-4-imidazolecarboxamide $(525 \mathrm{~m} \mu)$ than of 'amine' $(500 \mathrm{~m} \mu)$ so that the change observed was consistent with 
a substantial conversion of 'amine' to 5-amino-4-imidazolecarboxamide. Similar changes occurred when synthetic 5-aminoimidazole was substituted for 'amine' in the complete reaction system. No purple colour resulted when 'amine' or synthetic 5-aminoimidazole was omitted from the reaction mixtures, i.e. the changes did not represent new synthesis of 5-amino-4-imidazolecarboxamide.

The complete conversion of 'amine' or synthetic 5-aminoimidazole to 5-amino-4imidazolecarboxamide, as indicated by azo colour with an absorption maximum of $525 \mathrm{~m} \mu$, was not obtained even when complete reaction mixtures were incubated for longer periods. However, artificial mixtures of 'amine' and synthetic 5-aminoimidazole gave colours having a single absorption maximum intermediate between the maxima given by either component singly, the actual value depending on the relative proportions of the components. These results are consistent with the belief that 'amine' is 5-aminoimidazole (or a near derivative) and that it undergoes transformation to 5-amino-4-imidazolecarboxamide by living Escherichia coli B96.

\section{'Amine' and pigment formation}

Purified 'amine' was a pale greenish yellow crystalline solid which slowly darkened with the formation of deep purplish pigments which settled out of solution in small flocculent masses even during storage at $0-4^{\circ}$ in vacuo in the dark. This darkening and precipitation of pigments was most marked in relatively concentrated aqueous solutions $(5-20 \mu \mathrm{g}$. $/ \mathrm{ml}$.) and was always associated with loss of diazotizability. On chromatographic or electrophoretic development on paper, 'amine' left a trail of apparently similar purplish pigments; solutions of synthetic 5-aminoimidazole behaved similarly. The properties and manner of formation of these pigments indicate them to be substances of high molecular weight formed by polymerization involving the primary (diazotizable) amino group of 5-aminoimidazole. Hunter \& Hlynka (1941) produced evidence that pigment production from 5-aminoimidazole involved deamination followed by oxidative condensations; during the course of the present work it was observed that a remarkable series of yellow-orange and red zones appeared during the chromatographic development of relatively large amounts of synthetic 5-aminoimidazole. All these substances were less mobile than 5-aminoimidazole itself and may well have represented different stages of polymer formation. The readiness with which 'amine' undergoes transformation into pigments suggests that the pink pigment characteristic of Saccharomyces cerevisiae yeast 47 when it is accumulating 'amine' is derived from 'amine' itself.

\section{Formation of thiomethyladenosine by Saccharomyces cerevisiae, yeast 47}

Lones et al. (1958) showed that the addition of L-aspartate prevented the accumulation of 'amine' and hypoxanthine during the growth of Saccharomyces cerevisiae yeast 47 on their medium II; instead, adenine derivatives accumulated. One of these compounds was tentatively identified as thiomethyladenosine as follows. Concentrations of the adenine-containing compounds prepared according to Lones $e$ al. (1958) were submitted to separation by paper chromatography; the fastest-moving ultraviolet-absorbing spot $\left(\boldsymbol{R}_{\boldsymbol{p}}\right.$ value about 0.8$)$ was located, cut out and eluted. Various eluates were prepared and the material in them was shown to have the 
following properties: $(a)$ it gave positive reactions in the modified nitroprusside test of Csonka \& Denton (1946), and in Feigl's (1939) test for the $=\mathrm{C}=\mathrm{S}$ or $\equiv \mathrm{C}-\mathrm{SH}$ linkage; (b) on hydrolysis with $2 \mathrm{~N}-\mathrm{H}_{2} \mathrm{SO}_{4}$ at $100^{\circ}$ for $2 \mathrm{hr}$. it yielded a single purine derivative chromatographically and spectrophotometrically identical with adenine; (c) its ultraviolet spectrum in $0 \cdot 1 \mathrm{~N}-\mathrm{HCl}$ was indistinguishable from that of authentic adenosine $\left(\lambda_{\max } .257 \mathrm{~m} \mu\right)$; $(d)$ on electrophoresis in $0.05 \mathrm{M}$-phosphate buffer $(\mathrm{pH} \mathrm{7 \cdot 0})$ it migrated slowly towards the cathode $\left(0.066 \mathrm{~cm} . \mathrm{hr} .^{-1} / \mathrm{V} . \mathrm{cm} .^{-1}\right.$ as compared with $0.070 \mathrm{~cm} . \mathrm{hr} .^{-1} /$ V.cm..$^{-1}$ quoted for thiomethyladenosine by Baddiley, Cantoni \& Jamieson, 1953); ( $e$ ) it gave a positive but weak response in the orcinol pentose test; this accords with the report of Baddiley et al. (1953) that only $32 \%$ of the pentose present in thiomethyladenosine was detected after $\mathbf{4 0} \mathrm{min}$. heating in this test; $(f)$ it contained no phosphorus detectable by Allen's (1940) method after preliminary incineration with $60 \%(\mathrm{w} / \mathrm{v})$ perchloric acid. The absence of phosphate was also confirmed by its electrophoretic behaviour.

\section{DISCUSSION}

Taken in conjunction with previous work (Chamberlain \& Rainbow, 1954; Lones et al. 1958) the present work establishes the identity of the diazotizable amine accumulated by Saccharomyces cerevisiae yeast 47 under conditions of biotindeficiency as a mixture of 5-aminoimidazole riboside and a smaller quantity of the aglycone. It was not possible to determine whether the free base was present as such in the culture filtrate or whether it arose by hydrolysis during purification since the Bratton \& Marshall test did not distinguish between riboside and free base. The presence of traces of other diazotizable substances is not excluded.

The role of 5-aminoimidazole as an intermediate in purine biosynthesis at the nucleotide level is now well substantiated (Love \& Gots, 1955; Levenberg \& Buchanan, 1956; Lukens \& Buchanan, 1959). In the light of this knowledge, the accumulation of 'amine' hypoxanthine by yeast 47 may be interpreted as due to a block in aspartate synthesis conditioned by biotin-deficiency. First, the conversion of inosinic acid to adenylic acid involves the amino group of aspartate (Abrams \& Bentley, 1955). Secondly, the conversion of 5 -aminoimidazole ribotide to 5-amino4-imidazole( $N$-succinylo)-carboxamide ribotide via the intermediate 5-amino-4imidazolecarboxylic acid ribotide involves both aspartate and the incorporation of $\mathrm{CO}_{2}$ (Lukens \& Buchanan, 1959). Biotin is known to be involved in aspartate metabolism in yeast (Winzler, Burk \& du Vigneaud, 1944) and in bacteria (Lichstein \& Umbreit, 1947 ; Broquist \& Snell, 1951) and in bacterial $\mathrm{CO}_{2}$ fixation (Broquist \& Snell, 1951). Hence, biotin deficiency may well cause hypoxanthine, 5-aminoimidazole and its riboside to be excreted as the respective degradation products of the inosinic acid and 5-aminoimidazole ribotide (or the readily decarboxylated carboxy-5-aminoimidazole ribotide) which accumulate initially within the cell.

A supply of exogenous aspartate removes these biotin-dependent blocks in purine biosynthesis, and then adenine-containing compounds accumulate instead of 'amine' and hypoxanthine. The presence of thiomethyladenosine as one of these compounds is readily explained since it is a degradation product of S-adenosylmethionine, which accumulates in yeast cells grown on methionine-rich media 
(Schlenk \& DePalma, 1957). The following scheme illustrates the proposed relationships:

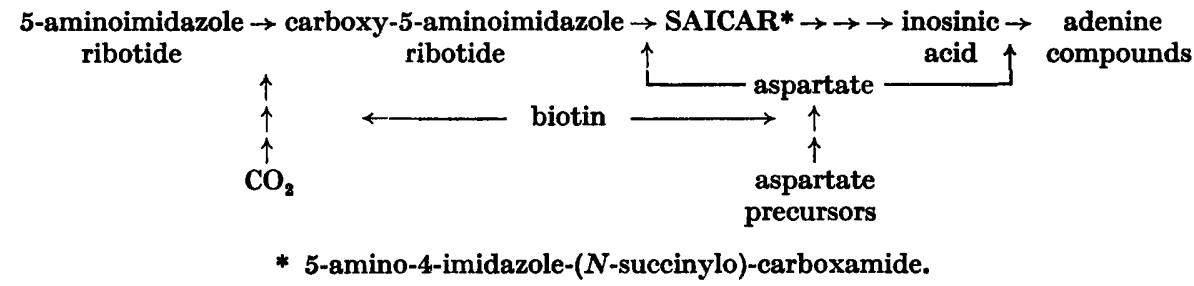

Moat et al. (1956) have also reported the accumulation of diazotizable amine, believed to be 5 -aminoimidazole riboside (Friedman \& Moat, 1958), by a biotindependent strain of Saccharomyces cerevisiae when growing in the presence of methionine; as with $S$. cerevisiae yeast 47 , adenine and aspartic acid inhibited its accumulation but, unlike yeast 47 , 'amine' accumulation was accompanied by that of inosine and not hypoxanthine.

The role of methionine in 'amine' formation is not clear. Methionine greatly enhances 'amine' production but it has no obvious effect on hypoxanthine accumulation, which appears to be solely the result of the imposed biotin deficiency. In liver slices methionine can give rise to formate and serve as a source of the $\beta$-carbon of serine (Siekevitz \& Greenberg, 1950). In 'amine' synthesis with Saccharomyces cerevisiae yeast 47 , methionine possibly plays a similar role in generating the onecarbon fragment required for the conversion of glycinamide ribotide to formylglycinamide ribotide, a precursor of 5-aminoimidazole ribotide.

We are indebted to the Department of Scientific and Industrial Research for a grant to one of us (J. D. W.) and to Dr J. S. Gots, Department of Bacteriology, University of Pennsylvania, for a culture of Escherichia coli B96.

\section{REFERENCES}

Abrams, R. \& Bentley, M. (1955). Transformation of inosinic acid to adenylic and guanylic acids in a soluble enzyme system. J. Amer. chem. Soc. 77, 4179.

Allen, R. J. L. (1940). The estimation of phosphorus. Biochem. J. 34, 858.

Ames, B. N. \& Mrtchell, H. K. (1952). The paper chromatography of imidazoles. J. Amer. chem. Soc. 74, 252.

Baddiley, J., Cantoni, G. L. \& Jamieson, G. A. (1953). Structural observations on 'active methionine'. J. chem. Soc. p. 2662.

Broquist, H. P. \& SNell, E. E. (1951). Biotin and bacterial growth. 1. Relation to aspartate, oleate and carbon dioxide. J. biol. Chem. 188, 431.

Buchanan, J. G., Dekker, C. A. \& Long, A. G. (1950). The detection of glycosides and non-reducing carbohydrate derivatives in paper partition chromatography. J. chem. Soc. p. 3162.

Chamberlain, N., Cutts, N. S. \& Rainbow, C. (1952). The formation of pigment and arylamine by yeasts. J. gen. Microbiol. 7,54 .

Chamberlain, N. \& Rainbow, C. (1954). The formation of diazotizable amine and hypoxanthine by a yeast: possible implications in the biosynthesis of purines. J. gen. Microbiol. 11, 80.

Csonka, F. A. \& Denton, C. A. (1946). Methionine determination in proteins and foods. J. biol. Chem. 163, 329.

DRURY, H. F. (1948). Identification and estimation of pentose in the presence of glucose. Arch. Biochem. 19, 455. 
Feigl, F. (1939). Qualitative Analysis by Spot Tests. London: Elsevier Publishing Co. Ltd.

Foster, A. B. (1952). Separation of the dimethyl-L-rhamnopyranoses by ionophoresis. Chem. \& Ind. p. 828.

Friedman, H. \& Mont, A. G. (1958). A comparison of nutritional and genetic blocks in the synthesis of purines by yeasts, moulds and bacteria. Arch. Biochem. Biophys. 78, 146.

GoTs, J. S. (1950). The accumulation of 4-amino-5-imidazolecarboxamide by a purinerequiring mutant of Escherichia coli. Arch. Biochem. 29, 222.

Hems, G. (1959). A mildly alkaline (pH 8) solvent for the isolation, by paper chromatography, of purines, pyrimidines, and their nucleosides and nucleotides. Arch. Biochem. Biophys. 82, 485.

Hunter, G. \& Hlynka, I. (1941). On a new indigoid formed from the glyoxaline (iminazole) nucleus. Canad. J. Res. 19B, 305.

Koessler, K. K. \& Hanke, M. T. (1919). Studies on proteinogenous amines. II. A microchemical colorimetric method for estimating imidazole derivatives. J. biol. Chem. 39, 497.

Levenberg, B. \& Buchanan, J. M. (1956). Formylglycinamidine ribotide and 5-aminoimidazole ribotide-intermediates in the biosynthesis of inosinic acid de novo. J. Amer. chem. Soc. 78, 504.

Lichstein, H. C. \& Umbreit, W. W. (1947). Biotin activation of certain deaminases. J. biol. Chem. 170, 423.

Lones, D. P., Rainbow, C. \& Woodward, J. D. (1958). A diazotizable amine produced by yeast: its chemical nature and factors affecting its accumulation. J. gen. Microbiol. $19,146$.

Love, S. H. \& Gots, J. S. (1955). Purine metabolism in bacteria. III. Accumulation of a new pentose-containing arylamine by a purine-requiring mutant of Escherichia coli. J. biol. Chem. 212, 647.

Lukens, L. N. \& Buchanan, J. M. (1959). Biosynthesis of the purines. XXIII. The enzymic synthesis of $N$-(5-amino-1-ribosyl-4-imidazolecarbonyl)-L-aspartic acid 5 'phosphate. J. biol. Chem. 234, 1791.

Moat, A. G., Wilkins, C. N. \& Friedman, H. (1956). A role for biotin in purine biosynthesis. J. biol. Chem. 223, 985.

Rabinowitz, J. C. (1956). Purine fermentation by Clostridium cylindrosporum. III. 4amino-5-imidazole-carboxylic acid and 4-aminoimidazole. J. biol. Chem. $218,175$.

Schlenk, F. \& DePalma, R. E. (1957). The formation of $S$-adenosylmethionine in yeast. J. biol. Chem. 229, 1037.

Siekevitz, P. \& GreEnBerg, D. M. (1950). The biological formation of formate from methyl compounds in liver slices. J. biol. Chem. 186, 275.

Winzler, R. J., Burk, D. \& DU Vigneaud, V. (1944). Biotin in fermentation, respiration, growth and nitrogen assimilation by yeast. Arch. Biochem. 5, 25.

Worwod, A. J. (1949). A technique for examining large numbers of bacterial culture filtrates by partition chromatography. J. gen. Microbiol. 3, 312. 